\title{
Interaction between Growth Factors and Retinoic Acid in the Induction of Kidney Tubulogenesis in Tissue Culture
}

\author{
H. David Humes ${ }^{1}$ and Deborah A. Cieslinski \\ Departments of Internal Medicine, VA Medical Center, Ann Arbor, Michigan 48105; \\ and University of Michigan Medical Center, Ann Arbor, Michigan 48109
}

\begin{abstract}
Kidney tubulogenesis is the initial step in renal organogenesis. The precise molecular determinants of this pattern formation are presently unknown, although soluble factors, such as growth factors, and insoluble factors, such as extracellular matrix molecules, most likely play fundamental roles in this process. To define the molecular determinants of renal proximal tubule morphogenesis, primary cultures of rabbit renal proximal tubule cells in hormonally defined, serumfree media were treated with transforming growth factor- $\beta_{1}$ (TGF- $\left.\beta_{1}\right)$, epidermal growth factor (EGF), and the retinoid, all trans-retinoic acid (RA), singly or in combination. Utilizing phase contrast and light and transmission electron microscopy, the simultaneous administration of TGF- $\beta_{1}(10 \mathrm{ng} / \mathrm{ml})$, EGF (1 $\left.\mathrm{nM}\right)$, and RA $(0.1 \mathrm{n} M$ ) transformed a confluent monolayer of renal proximal tubule cells within 5 to 6 days into three-dimensional cell aggregates containing lumens within the interior of the cell clusters. The lumens were bordered by tubule cells possessing a polarized epithelial cell phenotype with extensive microvilli formation and tight junctional complexes along the luminal border. All three factors were necessary and sufficient to induce this phenotypic transformation. Further studies demonstrated that $R A$ promoted the deposition of the $A$ and $B_{1}$ chains of laminin, a cell attachment protein of the basement membrane, in a small subset of proximal tubule cells in culture, as deduced by indirect immunofluorescent microscopy. Additional studies demonstrated that soluble purified laminin fully substituted for $R A$ in this system to promote renal tubulogenesis when combined with TGF- $\beta_{1}$ and EGF. These results demonstrate that the growth factors, TGF- $\beta_{1}$ and EGF, and the retinoid, $\mathbf{R A}$, promote tubulogenesis in adult renal proximal tubule cells in tissue culture in a manner reminiscent of inductive embryonic kidney morphogenesis. These observations define a coordinated interplay between growth factors and retinoids to induce pattern formation and morphogenesis. Furthermore, the demonstration of RA-induced laminin deposition as a critical event in this morphogenic process identifies laminin as
\end{abstract}

\footnotetext{
${ }^{1}$ To whom reprint requests should be addressed.
}

a possible target protein for $R A$ to act as a morphogen. 1992 Academic Press, Inc.

\section{INTRODUCTION}

Embryonic developmental organogenesis is dependent upon growth, differentiation, pattern formation, and morphogenesis. Each of these processes is dependent upon inductive interactions between cells. The identification of the inducing substances responsible for developmental organogenesis has been elusive, although recent work has generated interest in two classes of molecules, growth factors $[21,22,26]$ and retinoids $[30,31]$, as potential inductive morphogens in vertebrate embryos.

In this regard, most parenchymal organs develop from the inductive interaction between an epithelium and a mesenchyme $[9,15]$. The embryonic morphogenesis of the mammalian kidney, or metanephros, is a prime example of the importance of epithelial-mesenchymal interactions [24]. The kidney mesenchyme induces the ureteric epithelial bud, a caudal branch of the Wolffian duct, to migrate into the undifferentiated metanephric mesenchyme where it continues to branch and grow. Reciprocally, the branching and growing ureteric epithelium induces the metanephric mesenchyme to convert into tubular epithelium. The first step in metanephric tubulogenesis is an adhesion of mesenchymal cells to form multicellular aggregates. This initial aggregation step is followed by the development of tubule epithelial cell polarity and lumen formation. This induced pattern formation and morphogenesis is dependent on both cell proliferation and production of extracellular matrix components, primarily proteoglycans and laminin. Inhibitors of either DNA synthesis $[18,27]$ or proteoglycan synthesis $[5,6]$ prevent tubulogenesis at the early induction stage, while blocking antibodies to the cell binding domain of laminin inhibits the later stage of cell polarization and lumen formation without affecting the earlier developmental events of cell proliferation and aggregation [14].

Since renal proximal tubule cells have the ability to 

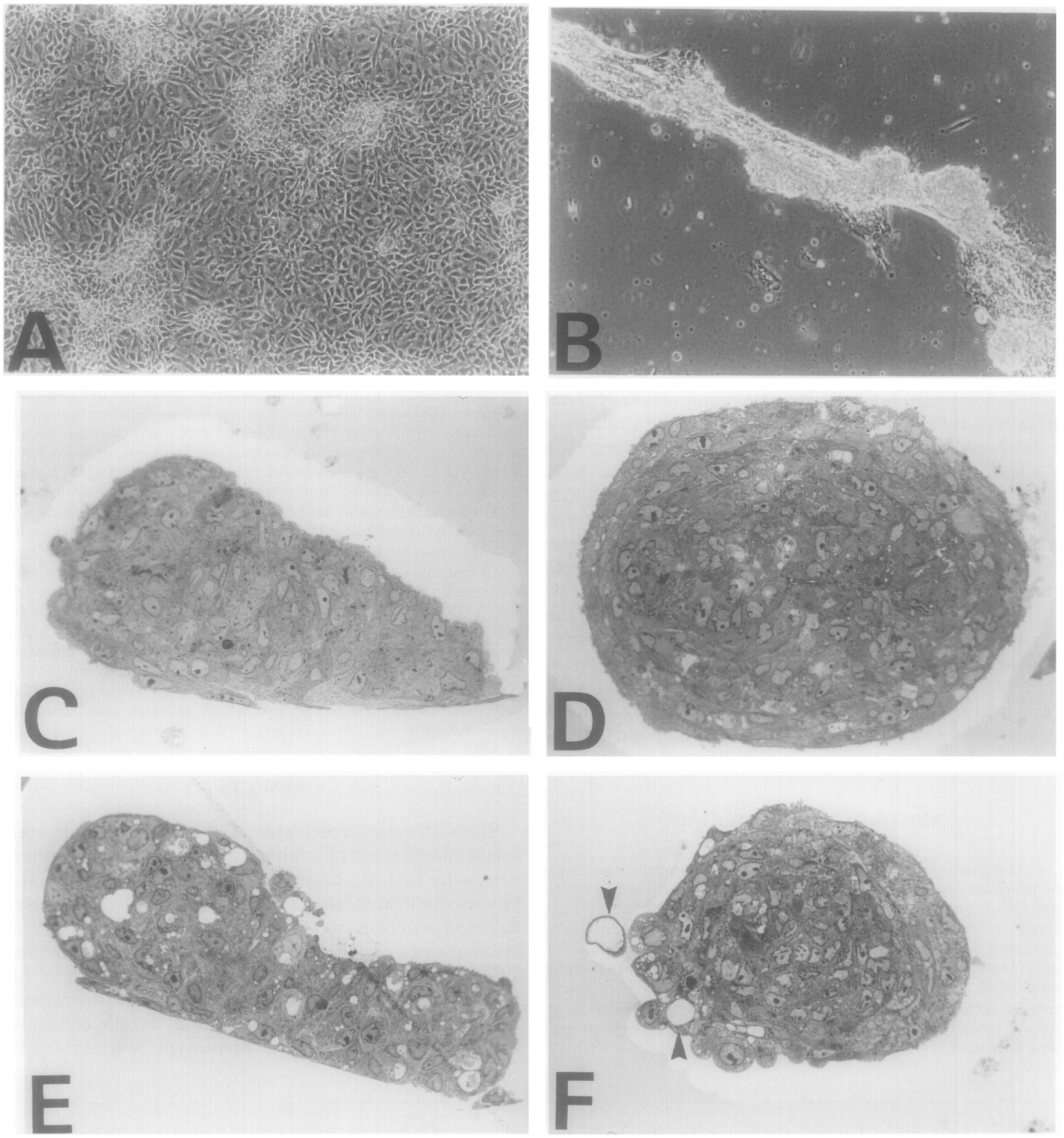

FIG. 1. Representative morphology of adult rabbit renal proximal tubule cells in tissue culture under various treatment conditions. Phase contrast microscopy (Mag $\times 25$ ) of a density-arrested, confluent monolayer of renal proximal tubule cells in tissue culture (A) and the transformed phenotype of tubule cells after simultaneous exposure to TGF- $\beta_{1}$, EGF, and RA (B). This treatment induced the monolayer to be transformed into an adherent condensation of cell aggregates which contained tubule lumens (see Figs. 2A-2C). Representative light microscopy (Mag $\times 100)$ of transformed phenotypes of confluent monolayers of renal tubule cells after various treatment conditions: TGF- $\beta_{1}(\mathrm{C})$; TGF- $\beta_{1}$ and EGF (D); TGF- $\beta_{1}$ and RA (E); TGF- $\beta_{1}$ and soluble purified laminin (F). For all experiments, TGF- $\beta_{1}$ at $10 \mathrm{ng} / \mathrm{ml}, \mathrm{EGF}$ at $1 \mathrm{n} M$, RA at $0.1 \mu M$, and laminin at $100 \mu \mathrm{g} / \mathrm{ml}$ were used. Exposure times were from 72 to $96 \mathrm{~h}$. Notice numerous vacuolizations with the TGF- $\beta_{1}$ and RA-treated condition (E). Most of these vacuoles were intracytoplasmic but some were primordial lumens (see Fig. 3). Intracytoplasmic lumens were occasionally seen in the TGF- $\beta_{1}$ and laminin-treated condition (arrowheads, F). 
regenerate after severe nephrotoxic or ischemic injury to form a fully functional and differentiated epithelium $[1,10]$, renal proximal tubule stem cells exist in adult kidneys. With the expectation that these stem cells can be isolated and grown in tissue culture, we undertook the present experiments utilizing primary cultures of adult rabbit renal proximal tubule cells grown in hormonally defined, serum-free medium in an attempt to identify substances that would promote kidney tubulogenesis. Since metanephric morphogenesis requires cell aggregation, proliferation, and polarization [24], various combinations of transforming growth factor- $\beta_{1}$ (TGF- $\beta_{1}$ ), epidermal growth factor (EGF), and the retinoid, all trans-retinoic acid (RA) were tested to assess induction of morphologic tubulogenesis. These factors were chosen for defined reasons. TGF- $\beta_{1}$ has been recently demonstrated to transform a monolayer of renal proximal tubule cells in primary culture into adhesive cell aggregates reminiscent of the initial aggregation stage of tubulogenesis [11]. This transformation is, in part, inhibited by proteoglycan synthesis inhibitors [19]. EGF is the most potent renal proximal tubule cell mitogen $[11,19]$, and RA has been shown to increase laminin production in embryonal cell lines by promoting laminin gene transcription $[2,20,32]$.

This report demonstrates that the combination of the growth factors, TGF $-\beta_{1}$ and EGF, with RA is necessary and sufficient to transform a confluent monolayer of adult renal proximal tubule cells in primary tissue culture into epithelial cell aggregates containing lumens bordered by cells with a differentiated polarized epithelial cell phenotype.

\section{METHODS AND MATERIALS}

Rabbit renal proximal tubule cells were grown in primary culture by previously reported techniques [11]. The cells were grown in 35mm Corning culture dishes with serum-free, hormonally defined Dulbecco's modified Eagle's: Ham's F-12 media $(1: 1, v / v)$ containing Lglutamine, penicillin, streptomycin, $50 \mathrm{nM}$ hydrocortisone, $5 \mu \mathrm{g} / \mathrm{ml}$ of insulin, and $5 \mu \mathrm{g} / \mathrm{ml}$ of transferrin. The cultures were maintained in a humidified $5 \% \quad \mathrm{CO}_{2} / 95 \%$ air incubator at $37^{\circ} \mathrm{C}$. Once confluent, various agents as described below were added in $20-\mu \mathrm{l}$ aliquots at various times to promote changes in morphologic phenotype or pattern formation.
Specimens for ultrastructural analysis were fixed with $2 \%$ glutaraldehyde in Sorenson's buffer ( $\mathrm{pH} \mathrm{7.2,310} \mathrm{mOsm).} \mathrm{Postfixation} \mathrm{oc-}$ curred in $1 \% \mathrm{OsO}_{4}$ followed by dehydration in ethanol. Specimens were transferred through propylene oxide into monomer mixture (poly/Bed 812A, Araldite, DDSA, and DMP-30) and polymerized at $60^{\circ} \mathrm{C}$. Thin sections were stained with uranyl acetate and lead citrate and examined in a Zeiss 9-S2 transmission electron microscope.

For immunofluorescence studies, renal tubule cells were grown to confluence and treated with various agents for time periods defined below. Cells grown on plastic culture dishes were fixed with $0.25 \%$ glutaraldehyde in PBS for $1 \mathrm{~h}$ at room temperature or overnight in a refrigerator. After fixation, culture dishes were washed with PBS containing $1 \%$ bovine serum albumin (BSA) and $0.05 \%$ Tween 20 to block and reduce nonspecific binding. The mouse monoclonal antibody in hybridoma culture medium was applied to the culture dishes for $3 \mathrm{~h}$ without dilution. The cells were then washed in PBS containing $1 \%$ BSA and $0.05 \%$ Tween 20 . The fluorescein-conjugated secondary antibody (goat anti-mouse) was diluted 1:80 in PBS containing $1 \%$ BSA and $0.05 \%$ Tween 20 and added to the preparation followed by incubation for $60 \mathrm{~min}$ at room temperature in the dark and in a hydrated container. The cells were washed in PBS containing $1 \%$ BSA and $0.05 \%$ Tween 20 , then covered with mounting media and a glass coverslip. Monoclonal antibodies were generous gifts from Eva Engvall (LaJolla Cancer Research Foundation, LaJolla, CA). The antibodies were produced from cloned hybridomas in cell culture [7]. The mouse monoclonal antibody (4C7) recognizes the $A$ chain and antibody $4 \mathrm{E} 10$ recognizes the $\mathrm{B} 1$ chain of human laminin. Both antibodies have cross-reactivity to rabbit laminin [23].

All reagents used were of the highest grade commercially available. All organic reagents were obtained from Sigma Chemical Co. (St. Louis, MO) unless otherwise indicated. EGF (recombinant human) was obtained from Amgen Biologicals (Thousand Oaks, CA), and TGF- $\beta_{1}$ (porcine platelets) from R \& D Systems (Minneapolis, MN). Laminin (Sigma) was purified from mouse EHS sarcoma cell line. TGF- $\beta_{1}$ was dissolved in $4 \mathrm{mM} \mathrm{HCl}$ and $1 \mathrm{mg} / \mathrm{ml}$ bovine serum albumin, EGF in aqueous buffer, RA in $95 \%$ ethanol, and laminin in aqueous buffer.

\section{RESULTS}

Simultaneous treatment of density-arrested, confluent monolayers of adult rabbit renal proximal tubule cells with TGF- $\beta_{1}$, EGF, and RA resulted in a dramatic phenotypic transformation characterized by condensed aggregates of cells in cord-like structures (Fig. 1). Evaluation of these cellular aggregates by light and transmission electron microscopy revealed the presence of lumen formation within the interior of the cell aggregates (Fig. 2). The lumens were bordered by tubule cells possessing polarized epithelial phenotype with extensive

FIG. 2. Light and transmission electron microscopy of renal proximal tubule cells in tissue culture treated with various agents. Simultaneous exposure of a confluent, density-arrested monolayer of renal tubule cells with TGF- $\beta_{1}$, EGF, and RA for $120 \mathrm{~h}$ promoted a transformation, as seen by light microscopy (Magnification $\times 35$ ), of the monolayer into adherent cell aggregates containing an area with a well-defined lumen sectioned longitudinally (A, black rectangle). Utilizing transmission electron microscopy, a higher power view of this area enclosed by the black rectangle in A clearly demonstrated that this lumen was bordered by tubule cells possessing polarized epithelial cell phenotype with well-developed apical microvilli $(C$, magnification $\times 800)$. Further magnification $(\times 2500)$ with electron microscopy of the area in $C$ defined by the black rectangle demonstrated tight junctional complexes (arrowheads) between the cells bordering the lumen near the apical surface (E). Treatment of a cell monolayer with TGF $-\beta_{1}$ for $72 \mathrm{~h}$ followed by exposure to EGF and soluble purified laminin for $48 \mathrm{~h}$ resulted in a similar transformation as depicted in B, D, and F. Light microscopy of a cell aggregate containing two lumens: a cross-sectional view (arrow) and a longitudinal view (arrowhead) $(B$, magnification $\times 35$ ). Transmission electron microscopy of the arca in $B$ enclosed by the black rectangle demonstrated that the lumen was bordered by tubule cells with a polarized epithelial phenotype (D, magnification $\times 700)$. Further magnification with electron microscopy $(F$, magnification $\times 2500)$ of the rectangular area in $D$ again demonstrated extensive microvilli and tight junctional complexes (arrowheads) along the apical surface of the cells. 

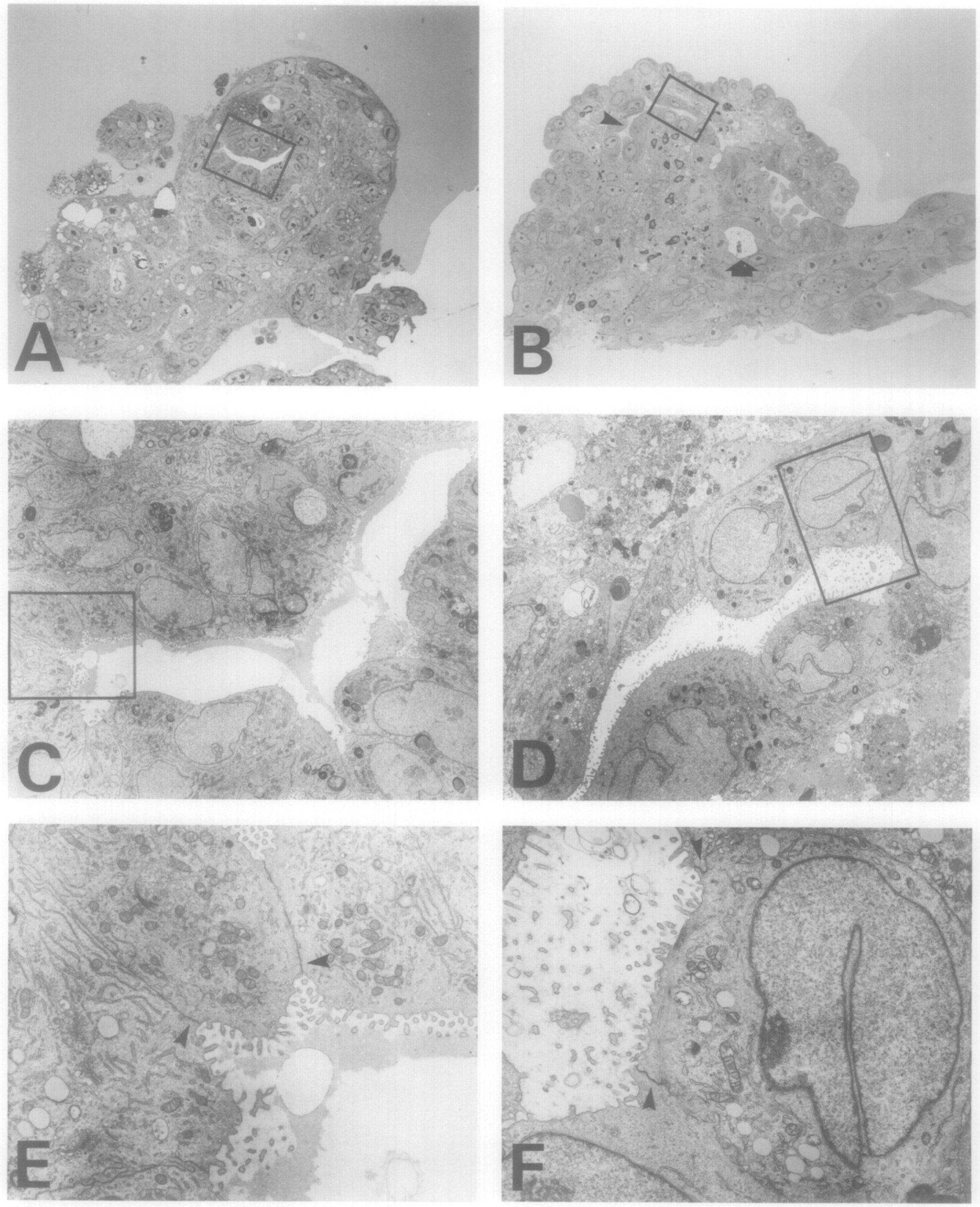


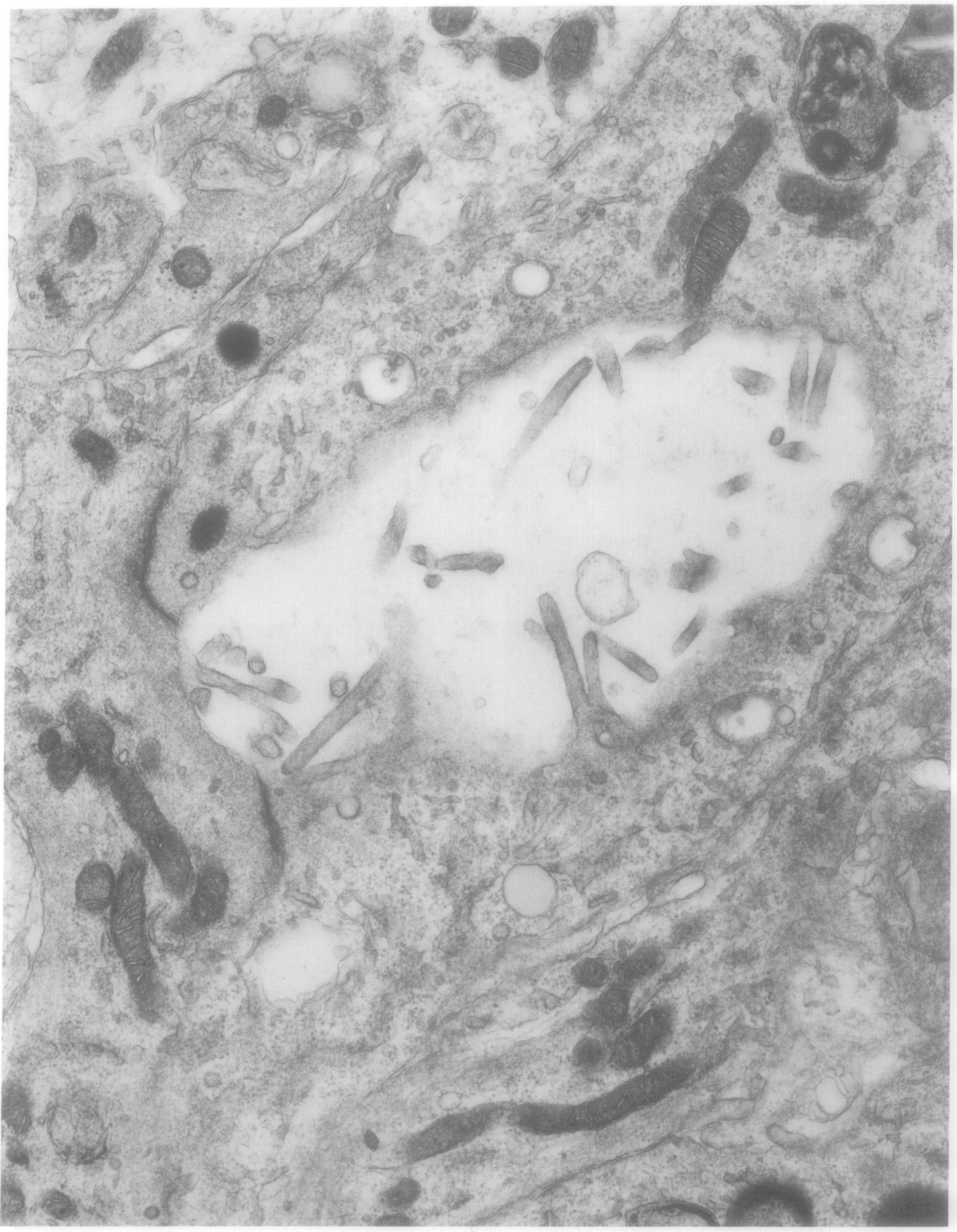


microvilli formation and tight junctional complexes along the luminal border (Figs. $2 \mathrm{C}$ and $2 \mathrm{E}$ ). The lumens and bordering polarized epithelial cells were surrounded by nonpolarized, adherent cells that did not possess tight junctional complexes.

All three factors were required for tubulogenesis in this system. As recently reported [11], addition of TGF$\beta_{1}$ to a density-arrested, confluent monolayer of renal proximal tubule cells resulted in a dramatic phenotypic transformation of the monolayer with migration and adhesion of the cells to form solid aggregates of adherent cells (Fig. 1C). Cells lining the surface of the cell aggregates possessed occasional broad-based microvilli and tight junctional complexes between cells exposed to the culture medium. Simultaneous treatment of a confluent monolayer with TGF- $\beta_{1}$ and EGF produced a similar morphologic transformation into cell aggregates which were, in general, larger than those seen with TGF- $\beta_{1}$ alone due to the greater number of adherent cells within the condensed aggregate (Fig. 1D). No lumen formation or epithelial-polarized phenotype was found. The simultaneous exposure of the epithelial monolayer to TGF- $\beta_{1}$ and RA, however, promoted intracytoplasmic vacuolization (Fig. 1E) and multiple primordial lumens in areas of cell-cell boundaries (Fig. 3). Well-developed microvilli and tight junctional complexes developed along the border of these vestigial lumens; however, without the presence of a growth promoter, i.e., EGF, these areas never developed into larger lumens with greater surface areas from an expanding number of bordering tubule cells with polarized epithelial phenotype, as observed with TGF- $\beta_{1}$, RA, and EGF (compare to Fig. 2). Treatment of the monolayer with RA alone or RA and EGF had no dramatic effect that changed the appearance of the monolayer; multicell aggregation did not develop in the absence of TGF- $\beta_{1}$.

The results suggest that these various factors are playing critical roles in tubulogenesis by promoting renal tubular cell adhesion and aggregation with TGF$\beta_{1}$, stimulating renal cell proliferation with EGF, and inducing tubule cell polarization with RA. Recent evidence suggests that the induction of renal tubule cell polarity in embryonic kidney tubule morphogenesis is dependent upon the local production of laminin [3, 14]. Further experiments were carried out to determine whether RA promotes laminin deposition in renal proximal tubule cells in primary culture. Using monoclonal antibodies with cross-reactivity to both rabbit laminin A and $B 1$ chains and indirect immunofluorescent techniques, treatment of density-arrested, confluent monolayers of renal tubule cells with RA resulted in deposition of both laminin A and B1 chains in a subset of cells in the monolayer (Figs. $4 \mathrm{C}$ and $4 \mathrm{E}$ ). Of note, less than $10 \%$ of the cells in the monolayer appeared to deposit laminin after RA exposure. Simultaneous exposure of renal tubule cells to TGF- $\beta_{1}, \mathrm{EGF}$, and RA also resulted in laminin deposition in a subset of cells (Figs. 4D and $4 \mathrm{~F}$ ).

To test whether laminin was the critical molecule whose deposition was promoted in renal tubule cells by RA for the development of epithelial cell polarity, the effect of laminin on tubule formation in tissue culture was assessed. Renal tubule cells, which had been previously exposed to TGF- $\beta_{1}$ for $72-96 \mathrm{~h}$ to form adherent cell aggregates, were then treated with EGF and purified soluble laminin, which resulted in formation of lumens bordered by cells possessing the polarized epithelial cell phenotype, similar to that observed with TGF$\beta_{1}$, EGF, and RA (Fig. 2). Once again, all three factors were necessary for tubulogenesis. Laminin alone had no obvious effect to alter the phenotypic appearance of the monolayer. Laminin plus TGF- $\beta_{1}$ resulted in occasional intracytoplasmic vacuolization but did not result in lumen formation (Fig. 1F).

\section{DISCUSSION}

The function of a tissue is critically dependent upon the spatial arrangement of its constituent cells, as clearly demonstrated in epithelia. Epithelial morphogenesis appears to be dependent upon both soluble and insoluble factors $[8,13,17]$, including growth factors and extracellular matrix (ECM) molecules. Of these factors, ECM components appear to be most critical in morphogenesis, since these molecules dictate whether individual cells proliferate or differentiate in response to growth factors. In this regard, an important role for laminin has been suggested for tubulogenesis in the embryonal development of the kidney or metanephros. Coincident with the onset of tubule cell polarity during differentiated nephrogenesis is the appearance of the A chain of laminin in the basal regions of the metanephric cell aggregates [17]. A functional role for laminin is suggested by the observation that blocking antibodies to the cell binding site of laminin inhibit cell polarization and lumen formation without affecting earlier developmental events of cell proliferation, adhesion, aggregation, and condensation [14]. Further support of a role for growth factors along with extracellular matrix in kidney tubulogenesis is the recent demonstration that EGF or transforming growth factor- $\alpha$ in the presence of Matrigel, a reconstituted basement membrane gel, promoted branching tubulogenesis of collecting duct-like cells in tissue culture [29].

FIG. 3. Transmission electron micrograph of a cell aggrcgate resulting from the treatment of a renal tubule cell monolayer in tissue culture with TGF- $\beta_{1}$ and RA for $72 \mathrm{~h}$ (Magnification $\times 13,000$ ). This field depicts a primordial lumen surrounded by tubule cells with developing microvilli and tight junctional complexes along the bordering cell surface. These vestigial lumens were formed in numerous locations in the cell aggregaters represented at lower power in Fig. 1E. 

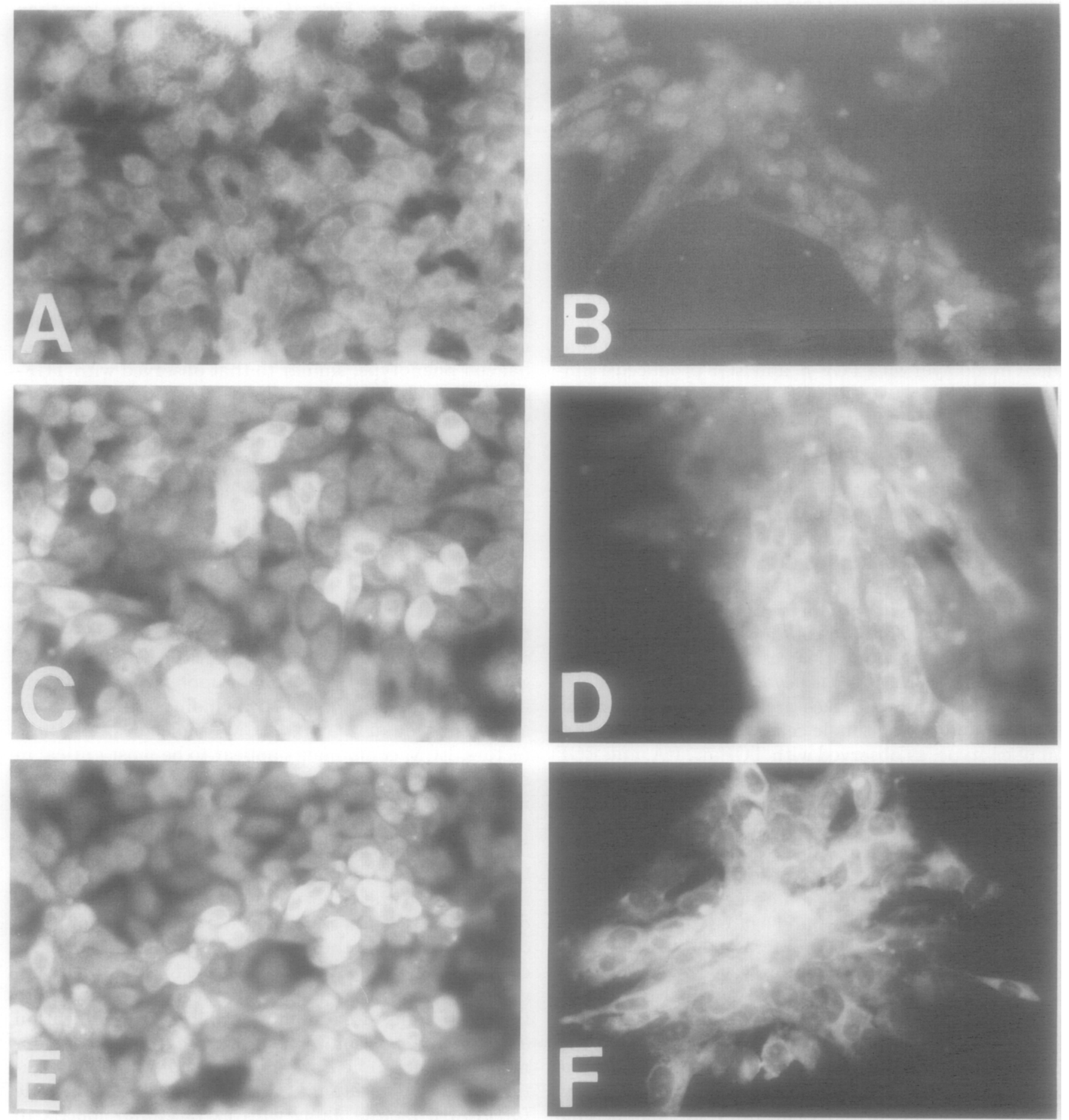

FIG. 4. Indirect immunofluorescent microscopy (magnification $\times 100$ ) of rabbit renal proximal tubule cells in primary culture under various treatment conditions utilizing monoclonal antibodies reactive to rabbit laminin $A$ and B1 chains. (A) Non-RA-treated control monolayer; primary antibody reactive to laminin A chain. (C) RA-treated monolayer for $96 \mathrm{~h}$; primary antibody reactive to laminin A chain. (E) RA-treated monolayer for $96 \mathrm{~h}$; primary antibody reactive to laminin B1 chain. (B) Cellular aggregate resulting from treatment with TGF- $\beta_{1}$, EGF, and RA for $96 \mathrm{~h}$; no primary antibody. (D) Cellular aggregate treated similarly to B; primary antibody reactive to laminin A chain. (F) Cellular aggregate treated similarly to B, primary antibody reactive to laminin B1 chain. No positive staining of cells was observed in untreated cells or without primary antibody.

The present results clearly demonstrate that three factors, TGF- $\beta_{1}$, EGF, and RA, were required to promote lumen formation and the morphologic differen- tiated epithelial cell phenotype. TGF- $\beta_{1}$ and RA promoted primitive luminal spaces between cells; but without a growth promoter, a fully developed enlarging 
lumen was not found. The need for EGF as a promoter of epithelial cell replication suggests that only a subset of cells in primary culture has the potential to differentiate into lumen forming cells with polarized epithelial phenotype. In fact, the morphology of the lumen containing cell clusters (see Figs. 2A and 2B) demonstrates that under these growth conditions the majority of cells develop into nonpolarized mesenchymal support cells and only a minority of cells develop into the differentiated epithelial cell phenotype. In this regard, current experiments are testing the previously suggested thesis [3] that the cells which respond to RA with laminin deposition are indeed the renal tubule stem cells capable of replication and terminal phenotypic differentiation.

A critical role for laminin in tubulogenesis was also directly confirmed by these studies. The observation that the combination of TGF $-\beta_{1}, \mathrm{EGF}$, and RA, induces tubulogenesis in tissue culture coupled with the facts that RA promoted laminin A and B1 chain deposition in renal tubule cells in primary culture and that purified laminin fully substituted for RA in conjunction with TGF- $\beta_{1}$ and EGF to promote kidney tubulogenesis strongly suggest that RA induction of renal tubule cell laminin deposition is the critical step in the later stages of epithelial cell polarization in kidney tubulogenesis. These results clearly demonstrate the manner in which $\mathrm{RA}$, as a morphogen, can promote pattern formation and differentiation by regulating the deposition of an extracellular matrix molecule.

Because only a small percentage of cells in primary culture has been demonstrated to respond to RA with laminin deposition, the current experiments have not explored the mechanism by which RA promotes the deposition of this extracellular molecule. With the recent establishment of a technique to growth select for renal proximal tubule stem cells, with the capacity to form lumens [12], current experiments are investigating the possibility that RA induces laminin gene expression with resulting increases in laminin protein synthesis as the mechanism of the observed effect of RA to enhance laminin deposition in a subset of renal tubule cells in primary culture.

We thank Dr. Theodore F. Beals for helpful discussions. We also appreciate the expert technical assistance of Ivan O. Sanchez, Sue Stuth, and Lyneen St. Denis. The excellent secretarial support of Sandra Dake is also appreciated. This work was supported by the VA Research Service and by grants from the National Institutes of Health (DK-30819 and DK-39155).

\section{REFERENCES}

1. Coimbra, T., Cieslinski, D. A., and Humes, H. D. (1990) Am. J. Phys. 259, F438-F443.
2. Dziadek, M., and Timpl, R. (1985) Dev. Biol. $111,372-382$.

3. Ekblom, P., Alitalo, K., Vaheri, A., Timpl, R., and Saxen, L. (1980) Proc. Natl. Acad. Sci. USA 77, 485-489.

4. Ekblom, M., Klein, G., Mugrauer, G., Fecker, L., Deutzmann, R., and Timpl, R. (1990) Cell 60, 337-346.

5. Ekblom, P., Lash, J. W., Lehtonen, E., Nordling, S., and Laxen, L. (1979) Exp. Cell Res. 121, 121-126.

6. Ekblom, P., Nordling, S., Saxen, L., Rasilo, M. L., and Renkonen, O. (1979) Cell Differ. 8, 347-352.

7. Engvall, E., Davis, G. E., Dickerson, K., Ruoslanti, L., Varon, S., and Monthorpe, M. (1986) J. Cell Biol. 103, 2457-2465.

8. Grant, D. S., Tashiro, K. L., Segui-Real, B., Yamada, Y., Martin, G. R., and Kleinman, H. K. (1989) Cell 58, 933-943.

9. Grobstein, C. (1967) Natl. Cancer Inst. Monogr. 26, 279-299.

10. Humes, H. D., Cieslinski, D. A., Coimbra, T., Messana, J. M., and Galvao, C. (1989) J. Clin. Invest. 84, 1757-1761.

11. Humes, H. D., Beals, T. F., Cieslinski, D. A., Sanchez, I. O., and Page, T. P. (1991) Lab. Invest. 64, 538-545.

12. Humes, H. D., and Cieslinski, D. A. (1991) J. Am. Soc. Neph. 2, 439. [Abstract]

13. Ingbar, D. E., and Folkman, J. (1989) J. Cell Biol. 109, 317-330.

14. Klein, G., Langegger, M., Timpl, M., and Ekblom, P. (1988) Cell 55, 331-341.

15. Kratochival, K. (1972) Tissue Interactions in Carcinogenesis, pp. 1-47, Academic Press, London.

16. Lehnert, S. A., and Akhurst, J. (1988) Development 104, 213273.

17. Madri, J. A., Pratt, B. M., and Tucker, A. M. (1988) J. Cell Biol. 106, 1375-1384.

18. Nordling, S., Ekblom, P., Lehtonen, E., Wartiovaara, J., and Saxen, L. (1978) Med. Biol. 56, 372-379.

19. Norman, J., Badie-Dezfooly, B., Nord, E. P., Kurtz, I., Schlosser, J., Chaudhari, An, and Fine, L. G. (1987) Am. J. Phys. 253, F299-F309.

20. Rogers, M. B., Watkins, S. C., and Gudas, L. J. (1990) J. Cell Biol. 110, 1767-1777.

21. Rosa, F., Roberts, A. B., Danielpour, D., Dart, L. L., Sporn, M., and David, I. (1988) Science 239, 783-785.

22. Ruiz i Altaba, A., and Melton, D. A. (1989) Nature 341, 33-38.

23. Sanes, J. R., Engvall, E., Butkowski, R., and Hunter, D. D. (1990) J. Cell Biol. 111, 1685-1699.

24. Saxen, L. (1987) Organogenesis of the Kidney, Cambridge University Press, Cambridge.

25. Schmid, P., Cox, D., Bilbe, G., Maier, R., and McMaster, G. K. (1991) Development 111, 117-130.

26. Slack, J. M. W., Darlington, B. G., Heath, J. K., and Godsave, S. F. (1987) Nature 326, 197-200.

27. Sobel, J. S. (1966) Science 153, 1387-1389.

28. Sorokin, L., Sonnenberg, A., Aumailley, M., Timple, R., and Ekblom, P. (1990) J. Cell Biol. 111, 1265-1273.

29. Taub, M., Yang, Y., Szczesny, T. M., and Kleinman, H. K. (1990) Proc. Natl. Acad. Sci. USA 87, 4002-4006.

30. Thaller, C., and Eichele, G. (1987) Nature 327, 625-628.

31. Tickle, C., Roberts, B. M., Lee, J., and Wolpert, L. (1982) Nature 296, 564-565.

32. Vasios, G. W., Gold, J. D., Petkovich, M., Chambon, P., and Gudas, L. (1989) Proc. Natl. Acad. Sci. USA 86, 9099-9103.

33. Wilcox, J. N., and Derynck, R. (1988) Mol. Cell. Biol. 8, 34153422 . 